\section{Automatic enrollment and employer match: an experiment with the choice of pension plans}

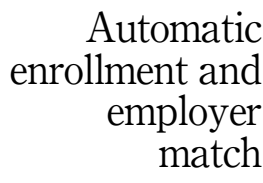

281

Antonio Gualberto Pereira

Department of Accounting, Federal University of Bahia (UFBA), Salvador, Brazil, and

Luís Eduardo Afonso

Department of Accounting and Actuarial Science, University of São Paulo, São Paulo, Brazil
Received 2 July 2019 Revised 12 November 2019 Accepted 16 December 2019

\begin{abstract}
Purpose - The purpose of this study is to identify arrangements of fully funded defined contribution (FF-DC) pension plans associated with the continuity of retirement savings.

Design/methodology/approach - The authors adopted an experimental design composed of a control group and two treatment groups. In all groups, individuals made decisions throughout nine periods: five during the working period and four at the postretirement stage. The authors asked participants if they wanted to join a pension plan, and which plan. The authors offered three plans with different risk profiles: plan 1 (high risk), plan 2 (moderate) and plan 3 (low risk) and one risk-free plan, plan 4. In treatment groups 1 and 2 , there was an automatic enrollment of the participants in the default plan (moderate risk), and in the following periods they had to decide whether to continue contributing, and in this case, to which plan, with a defined percentage.

Findings - In treatment scenarios, participants chose the riskiest plan in all periods of the experiment, and most of them chose the risk-free plan in period 5. These findings suggest that pension plans with automatic enrollment, employer matching and low risk foster the continuation of retirement savings.

Research limitations/implications - The research has as limitation the fact that the sample is not representative of the population and therefore does not allow generalizations. This is because the authors use social media ads to prospect respondents.

Practical implications - The research's findings can be relevant for the design of public policies for private pension plans, suggesting that compulsory automatic enrollment can be used as default in plans offered by the employers. The results encourage the inclusion of behavioral elements in the design of the pension system, paying attention to the nudges. In this sense, it is possible to increase participation in the pension plan and develop low cost programs to increase the amount accumulated by people before retirement.

Social implications - Decision-making architecture, such as automatic enrollment, can improve individuals' retirement decisions, affecting savings and welfare in the long run.

Originality/value - Although the effect of pension plan designs is widely studied in other countries, such as the United States and United Kingdom, the authors are unaware of a national empirical research that seeks to understand how different arrangements affect an individual choice through an experiment.
\end{abstract}

Keywords Automatic enrollment, Experiment, Pension plan, Retirement, Behavioral economics

Paper type Research paper

\section{Introduction}

The primary function of a pension system is to serve as a mechanism for reallocation of workers' income, from working life to retirement. For this process to be efficient, it is

(C) Antonio Gualberto Pereira and Luís Eduardo Afonso. Published in Revista de Gestão. Published by Emerald Publishing Limited. This article is published under the Creative Commons Attribution (CC BY 4.0) license. Anyone may reproduce, distribute, translate and create derivative works of this article (for both commercial and non-commercial purposes), subject to full attribution to the original publication and authors. The full terms of this license may be seen at http://creativecommons.org/licences/by/4.0/legalcode

Antonio Gualberto Pereira is grateful to Coordenação de Aperfeiçoamento de Pessoal de Nível Superior (Capes) for its support to his $\mathrm{PhD}$ scholarhip. 
REGE 27,3

necessary to take a set of decisions, in an environment of uncertainty, and for an extensive time horizon. One of the most important is the amount of savings to meet the needs in old age. Such choices are likely to be wrong if individuals are in charge of them. One solution would be a government intervention, by defining the amount they should save. There is also a kind of myopia, which makes these decisions worse (Feldstein \& Liebman, 2002). Given this picture, a pay-as-you-go (PAYG) regime is an example of the State's paternalist intervention (Mulligan \& Sala-i-Martin, 1999). Government defines the contribution rates of active workers and transfers the resources to the pensioners in the same period.

However, people frequently reject this paternalist concept of forced savings because it relies on differences in the discount rates between citizens and the government. It implicitly assumes that governments are more "oriented to the future" and more patient. On the other hand, another perspective of the paternalist-forced savings regards the gap between long-term goals and short-term behaviors, also known as time inconsistency. This argument seems to be broadly accepted (Cremer \& Pestieau, 2011). Individuals, however, seem to discount the future from the present faster than between different dates in the future (Strotz, 1955). Events derived from this phenomenon are procrastination and subsavings (Cremer \& Pestieau, 2011).

In countries where the responsibility of retirement savings lies with the workers, there has been an expansion of fully funded defined contribution (FF-DC) regimes, partially funded by employers or fully by workers. In these plans, employees accumulate resources for their retirement through voluntary or mandatory contributions to their pension account. Companies offer a wide variety of pension plans to employees, and the risk profile of the participants clearly influences the choice of plans - more risk-averse individuals choose less risky plans (Cox \& Harrison, 2008; Hey, 2008).

Findings from Behavioral Economics, by Shefrin and Thaler (1988) and Graham and Isaac (2002) provided insights for a better understanding of an individual savings decision. The Behavioral Life-Cycle Model adds features such as self-control, mental accounting and framing to the structure originally developed by Modigliani and Brumberg (1954). Important dimensions such as internal conflict, temptation and willpower can also be relevant for predicting savings behavior (Shefrin \& Thaler, 1988). Knoll (2010), in a comprehensive literature survey, deepens these arguments, stressing that people can behave in a suboptimal way, especially regarding their savings. Based on this theoretical background, Xiao and Porto (2019) provide evidence that a kind of bias may explain why consumers give more importance to spending instead of saving, which leads to inadequate wealth accumulation.

In general, people use heuristics to make decisions about retirement savings. This and other shortcuts can lead to systematic biases in decisions on the amount of contributions and choice of portfolio (Benartzi \& Thaler, 2007). The authors show evidence that enrollment in pension plans that depend on individual decisions is low. Similarly, individuals decide to save by considering certain rules of thumb (Benartzi \& Thaler, 2007; Binswanger \& Carman, 2012; Kling, Phaneuf \& Zhao, 2012; Mullainathan \& Thaler, 2000). When it comes to choosing the investment portfolio, participation rate decreases when there is a large number of options (Benartzi \& Thaler, 2007). Keim and Mitchell (2018) achieved a similar result, showing that the reduction of fund options can change savings and improve choices.

Although advice and information can enhance understanding of pension plans, behavioral barriers, such as myopia, cynicism and inertia, may still inhibit actions to save for retirement (Foster, 2017). The design of retirement plans can include strategies to encourage certain behaviors and restrain others. An alternative is to modify the standard (default) choice from opt in (join the plan) to opt out (leave the plan), a typical nudge of the libertarian paternalism, which can help people make better decisions (Kahneman, 2012). There is much empirical evidence that changing the default choices is an effective way to improve savings decisions (Butt, Donald, Foster, Thorp, \& Warren, 2018; Carroll, Choi, Laibson, Madrian, \& Metrick, 2009; Nishiyama \& Smetters, 2014). 
Based on these arguments, this paper sought to identify potential arrangements of DC pension plans associated with the continuity of resource allocation for retirement. Therefore, we intended to answer the following research question: Are fully funded defined contribution (FF-DC) pension plans, with automatic enrollment and low risk, associated with the continuity of resource allocation for retirement?

The article has five sections, including this introduction. Section 2 presents the theoretical framework; Section 3 describes the research methodology and experimental protocol. We present the research findings and conclusions in Sections 4 and 5.

\section{Pension plan design: automatic enrollment, defaults and employer matching}

People are impulsive, inconsistent over time and unable or unwilling to express their longterm interests (Clark, 2011), which can lead to subsavings and procrastination in intertemporal decisions. There are several means for an employee to fail in saving for retirement: postpone enrollment in the plan, choose a low contribution rate or make an inappropriate asset allocation (Munnell \& Sundén, 2004). Actions oriented to encourage individuals' commitment are a way to maximize their welfare.

The literature documents several behavioral patterns: individuals procrastinate when faced with complicated choices, which may reduce their retirement savings (Carroll, Choi, Laibson, Madrian, \& Metrick, 2009). In contrast, Choi, Laibson and Madrian (2009) and Beshears, Choi, Laibson and Madrian (2010) show that the simplification of the enrollment process leads to a considerable increase in participation. Automatic enrollment is a technique associated with the nudge concept, in which eligible employees (often of low or medium pay) are automatically enrolled in DC schemes, based on the assumption that they are not prepared to actively join the pension plan (MacLeod, Fitzpatrick, Hamlyn, Jones, Kinver, \& Page, 2012). Dobrescu, Fan, Bateman, Newell, Ortmann and Thorp (2017) explain that default functions act as a nudge or a less resistance path, both over time and between decisions.

Sandbrook and Ravi-Burslem (2019) suggest some attitudinal factors that help explain mistakes in retirement decisions. The first is that this issue causes negative emotional responses. The second is that individuals do not really care about retirement (although a significant part agrees with automatic enrollment). In addition, most people do not have adequate knowledge to make the right decisions. As Beshears, Choi, Laibson, and Madrian (2017) highlight, the Plan Sponsor Council of America [PSCA] (2016) announced that 58\% of the 401(k) plans automatically enroll their employees. In 2016, United Kingdom, Italy and New Zealand had introduced automatic enrollment (Collard, 2013; Prabhakar, 2017).

Rudolph (2019) presents the case of automatic enrollment of federal civil servants in a pension plan in Brazil. In November 2015, Funpresp changed its status to an opt-out system. As a result, there was a reduction in the exit rates of the pension plan from $71 \%$ to $14 \%$, from November 2015 to November 2017.

The literature on default plans shows that such a strategy tends to keep people tied to preestablished choices (Choi, Laibson, Madrian, \& Metrick, 2003, 2004; Cronqvist \& Thaler, 2004; Madrian \& Shea, 2001). In this perspective, if individuals remain passive and do not choose carefully the defaults, they will get suboptimal results upon retirement (Carroll, Choi, Laibson, Madrian, \& Metrick, 2009; Dobrescu, Fan, Bateman, Newell, Ortmann, \& Thorp, 2017; Goda \& Manchester, 2013). Beshears, Choi, Laibson and Madrian (2013) observe that $90 \%$ of the employees with automatic enrollment in the company's pension plan kept their assets invested in default funds, and around two-thirds invested all their assets in these funds. Choi, Laibson, Madrian and Metrick (2002) provided further evidence, indicating that automatic enrollment increases the participation rate, but the vast majority of employees accept the default contribution rate and the allocation of their assets in the default 
REGE 27,3

\section{4}

investments. An explanation is behavioral inertia (Choi, Laibson, Madrian, \& Metrick, 2004; Madrian \& Shea, 2001); many studies show that most participants of pension plans accept the default option offered (Bütler \& Teppa, 2007; Choi, Laibson, Madrian, \& Metrick, 2003).

There is a clear relationship between the pension plan design and savings and investment choices. Pension plans' participation largely increased by changing default from nonparticipation to participation, as well as changes in the contribution rates, and allocation of assets to the default linked to automatic enrollment (Benartzi, 2001; Beshears, Choi, Laibson, \& Madrian, 2008, 2011, 2018; Choi, Laibson, Madrian, \& Metrick, 2003, 2004, 2009; Clark, Hanson, \& Mitchell, 2016; Madrian \& Shea, 2001).

Participants fail to make their choices for lack of knowledge on investments, inadequacy of the available alternatives or anomalies in human behavior (Basu \& Drew, 2007). In addition, Brown, Kapteyn, and Mitchell (2016) indicated that a significant group of individuals was making inconsistent pension decisions, which pension plans could improve by communicating proper information to employees.

In the case of investor's inertia and lack of attention (Agnew, Anderson, Gerlach, \& Szykman, 2008; Ameriks \& Zeldes, 2004; Dahlquist \& Martinez, 2015; Madrian \& Shea, 2001; Mitchell, Mottola, Utkus, \& Yamaguchi, 2006; Samuelson \& Zeckhauser, 1988), it is assumed that pension investors are often involuntary investors (pension is compulsory), and many of them do not care about their forced savings or either overdraft them.

Another strategy used by large companies to stimulate employees' participation in pension plans is the employer contribution match. US companies widely offer this strategy; thus it has little impact (Andrews, 1992; Choi, Laibson, Madrian, \& Metrick, 2002; Papke \& Poterba, 1995). According to Choi, Laibson, Madrian and Metrick (2002), the match of an employer may increase the contribution to defined contribution plans - in the case of the 401(k) plans. However, in a study involving automatic enrollment and employer contribution match, Beshears, Choi, Laibson and Madrian (2010) found that the participation rate slightly decreased when employers withdrew or reduced their match. Such a finding suggests that companies do not need to make an equal contribution to achieve a broad participation. On the other hand, Nessmith, Utkus and Young (2007) identified that automatic enrollment led to lower contribution rates, since participants who would voluntarily contribute with a higher rate remained at the lowest default contribution rates.

Even slight nudges can be important. Clark, Hammond, Morrill, and Khalaf (2017) showed that simple interventions such as flyers have positive impacts for increasing retirement safety. However, this result works for individuals already enrolled in the pension plan. In another study, nudges influenced a huge number of Swedish citizens to choose their pension portfolio (Cronqvist, Thaler, \& Yu, 2018).

\section{Methodological procedures}

\subsection{Research hypotheses}

The literature review mentions studies that seek to reduce the effect of behavioral distortions or anomalies through better pension plans, such as participants' automatic enrollment (Choi, Laibson, Madrian, \& Metrick, 2003) and new designs (Agnew, Anderson, Gerlach, \& Szykman, 2008; Basu \& Drew, 2007; Beshears, Choi, Laibson, \& Madrian, 2013; Pang \& Warshawsky, 2008). Based on these studies, described in Section 2, we developed the following hypotheses:

H1a. Individuals automatically enrolled in a supplementary pension plan do not change their decision in future choices.

H1b. A supplementary pension plan with lower risk receives more individual admission compared to other plans. 


\subsection{Research subjects}

The group of research subjects consisted of people who had access to the questionnaire hosted on an online platform (Questionpro $($ )), made available by paid ads in social networks $($ Facebook $\mathbb{C}$ and LinkedIn $($ ) $)$, or who were invited to participate in the research through links available in the researchers' social networks. In addition, we sent invitations to people registered in the researchers' electronic contact lists. Participation was voluntary, and we did not use any criteria for the inclusion or exclusion of participants.

This form of research advertising may have caused a sampling bias: a profile of both high education and average income per capita above the Brazilian rates. We had to be careful on the generalization of results because samples in network studies "are typically nonrepresentative, and non-representativeness of network data may be caused by the sampling strategy itself" (Handcock \& Gile, 2010).

In another study, Osman's findings (2017) indicate that people with higher income and higher education are more likely to join a private pension plan. In this sense, the sample bias, unintentionally, comprised the population range most involved in decisions regarding supplementary social security.

Considering that we chose to make the questionnaire available through the Internet, by using social networks as the advertising method, we adopted a simplified version of the free and clarified consent Term. The first part of the questionnaire introduced the research, disclosed the researchers' contacts, and requested the participant's consent. In compliance with Regulation 466/12 issued by Brazil's National Health Council [Conselho Nacional de Saúde], which determines the voluntary participation in research involving human beings, we decided not to conduct an experiment based on effective payments.

Ahern (2005) summarized the advantages that an online research offers to researchers and research subjects. For the researcher, it can: (1) be less expensive; (2) reach a large group of potential participants; (3) increase the access to sensitive questions, cultural groups and "hidden populations"; (4) reduce data collection time; (5) enhance control; (6) increase accuracy and efficiency in both data collection and analysis. As to the advantages for research subjects, they involve: (1) increased anonymity; (2) possibility to provide information at their own pace; (3) increased willingness to participate in the research and (4) ease of use.

\subsection{Pilot test}

To test the semantic and contextual understanding of the scenarios for the experiment, we carried out a pilot test. To that end, we sent by e-mail a preliminary version of the experiment to 25 persons, from March 9, 2015 to March 28, 2015. They were all academic experts, and we incorporated their suggestions into the final version of the electronic questionnaire.

\subsection{Data collection}

We carried out a scenario-based experiment to find out the choices related to defined contribution supplementary pension plans. At the end of the experiment, participants answered some questions in order to identify some social-demographic attributes of the sample. We conducted both the collection and the experiment with the assistance of the online platform Questionpro ${ }^{C}$, and made them available to participants in the Internet. Hence, there was no experimental session in the laboratory, and participants could answer the questionnaire from anywhere with an Internet access.

We hosted the instrument at the platform used to manage the research, which received a virtual address (http://www.decisoesdeaposentadoria.questionpro.com). In the research presentation, we informed participants that they should consider no inflation over time, i.e. all the amounts were real, not nominal. No minimum or maximum time was predetermined for the participant to answer the questionnaire, and he could even save the answers and

\section{Automatic enrollment and employer match}


REGE 27,3

\section{6}

resume it later. Respondents spent, on average, $17 \mathrm{~min}$ and $13 \mathrm{~s}$ to complete the questionnaire.

\subsection{Experiment description and experimental scenarios}

The experiment aimed to mimic individual savings decisions in an FF-DC pension system, throughout the working life (five experimental periods), to finance benefits during retirement (four periods).

The research management platform (Questionpro@) randomly separated the participants between the control group and the two treatment groups. In order to keep randomness and balance in the distribution of participants among groups, the researcher changed, every day, the version available to the potential participant on the platform, through the virtual address of the questionnaire. In other words, although we kept the same virtual address published in social networks, every day we sent to new-interested parties different versions of the instrument, concerning the available link. Next, we defined experimental scenarios for the control group and for the two treatment groups.

After clicking the link, the participant had access to a set of information, regarding the completion of the questionnaires and the rules for the decision-making process. The experiment began when the individual started his working life (period 1) and finished after nine periods: five simulating the years in the labor market and four simulating the retirement period.

In each of the five periods before retirement, the individual received a hypothetical income of US\$260. All the monetary amounts were converted from Brazilian currency (BRL) to US dollars (US\$), using the average exchange rate (3.8461) for the experiment period - from August to December 2015. In these five periods, there was a typical consumption-savings intertemporal decision: the individual should decide if his income would go to consumption, and how much he would save, that is, contribute to the FF-DC pension plan. If the individual decided to save part of his income, he should choose among different plans (described below). After retirement, he would indicate, at each period, the percentage he intended to redeem from the amount accumulated during his working life. We then converted automatically the amount of the retirement, through a conversion table, into the amount that the researcher would donate to a philanthropic entity, which the participant would choose from a list available at the end of the questionnaire. The amount of the retirement benefits in the last four periods consisted of two parts: the contributions made in the five periods before retirement (and the interest rates earned), plus a lump sum benefit of US\$26 per period.

\subsubsection{Conversion scale}

We adapted a conversion scale developed by Hey (2008), where conversion is similar to the transformation of utility into happiness (assuming that donating is a proxy of happiness for most people). The more the individual converts/consumes in the experimental scenarios, the more real money he could donate for charity in that period, "but real money increases with a decreasing rate of consumption" (p. 1). For example, US\$156 in the experiment converted into real money becomes US $\$ 0.21$, US $\$ 182$ becomes US $\$ 0.30$ and US $\$ 208$ becomes US $\$ 0.38$. Thus, as pointed by Hey (2008), if we have an increase in conversion/consumption from 156 to 182, the earnings in the experiment increase by US\$0.09, while an increase in conversion/ consumption from 182 to 208 means an increase by US\$0.08 in earnings. In this sense, as suggested by economic theory, participants are encouraged to reduce their conversion/ consumption over their life periods (years).

The conversion scale mimics a convex utility function, and this "function is increasing at a decreasing rate (that is, marginal utility is declining) - hence, the reason for this shape of the conversion scale" (Hey, 2008, p. 28). Figure 1 shows the scale used in the experiment. 


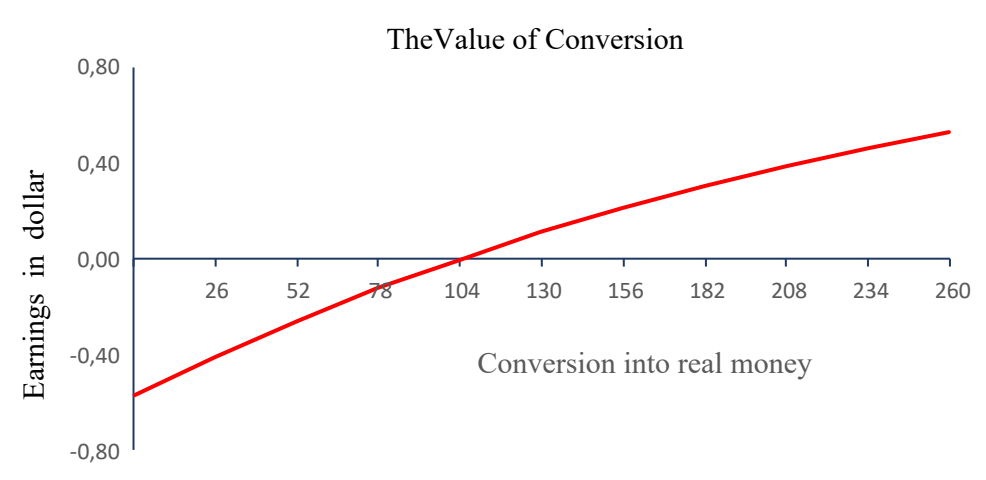

Source(s): Adapted from Hey (2008)

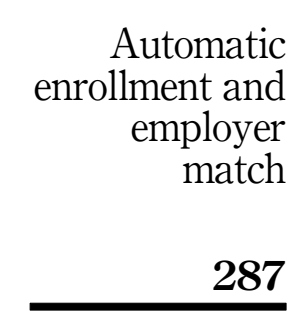

Figure 1.

The conversion scale

The conversion scale is the rate by which the money that the participant earned was converted in an amount for donation at the end of the research. If the amount consumed in any period were lower than US $\$ 104$, the participant would "gain" a negative amount - that is, he would lose money. For example, US $\$ 26$ consumed would become US $\$ 0.41$, US\$104 would become US $\$ 0.00$, US $\$ 182$ represented a gain of US $\$ 0.30$ and so forth. These amounts illustrate the conversion process of the "experimental money" into "real money" defined in the conversion table (Hey, 2008).

To explain the conversion process, suppose that the participant consumed all his income in each of the periods prior to retirement; therefore, he saved nothing. Retirement would be only the flat benefit of US $\$ 26$. As the experiment lasted nine periods, the conversion generated by this participation was 260.00 for each working period and 26.00 for each period after retirement. Therefore, the participant's earnings (using the conversion scale), in US\$, would correspond to US\$0.53 in each work period (1 to 5) and US\$0.41 in each period after retirement (6 to 9). In other words, the participant gained US $\$ 1.01$ (US $\$ 0.53$ in each of the five periods, less US $\$ 0.41$ in each of the remaining four periods).

As for the treatment groups, in the initial period each participant enrolled in the default pension plan, which was the medium risk plan. If the participant remained in this plan in the following periods, all contributions would have a counterpart in the same amount, paid by the researcher (mimicking the mechanism of parity contributions by the employer, adopted by private pension plans). However, the participant could leave the pension plan defined by the researcher, or not contribute to it. In the event of leaving, the parity contribution ended. At each period, we asked the participant if he wanted to remain in the pension plan or leave it.

As mentioned before, the participant could choose between three risky plans, designated plan 1, plan 2 and plan 3, and a risk-free plan, plan 4. Each of the first three plans had two possible real interest rates per period, to capitalize the accumulated resources, with an equal probability of 0.5 associated to each rate. These alternatives were based on Hey (2008). Before making a decision on the pension plan, individuals received information on interest rates and probabilities. However, when opting for a plan, the participant did not know, ex ante, what the interest rate would be. The rate was randomly determined ex-post.

In plan 1, the riskiest plan, the interest rates were $1.4 \%$ and $5.2 \%$, which gave an expected interest rate of $3.3 \%$ per period. In plan 2 , the intermediate plan, the interest rates were $1.5 \%$ and $4.3 \%$ (expected value of $2.9 \%$ ). In the less risky plan, plan 3 , the interest rates were 1.6 and $3.4 \%$ (expected value of $2.5 \%$ ). Finally, in plan 4 , the deterministic interest rate was $2.1 \%$ per period. 
REGE 27,3

\section{8}

If the participant contributed US\$26 to plan 1, this amount could increase to up to US\$26.36 or US\$27.35; if he contributed US\$26 to plan 3, the amount could increase to US $\$ 26.42$ or could increase to US $\$ 26.88$. If the contribution were for plan 4, the amount would increase to US\$26.55. It is important to note that the interest rate in any period or plan was independent of the rate in other periods and plans. The participant could not change his choice of plan based on past contribution decisions. It was a once-for-all choice. For example, if he decided to save US\$26 in period 1 in plan 2, this amount remained invested in plan 2 for periods 2, 3, 4 and 5. Upon retirement, in period 6, the participant received the flat benefit of US $\$ 26$ per period, plus an additional amount determined by his contributions during the five working periods and by the interest rate (which corresponds to the supplementary pension benefit).

After completing the experiment, the researchers calculated the retirement amount for each subject and, at the same time, the amount to donate to one of the philanthropic entities, for each participation. This amount was sent to the institutions selected, and the receipt was available for interested parties upon request. The amount of donations per institution was disclosed in the social networks of one of the researchers.

\subsection{Instrument application}

The participants of the Control Group could choose a pension plan and save for retirement, but their enrollment was not mandatory. Individuals in Treatment Group 1 were automatically enrolled in a default risky plan and they could make savings decisions as well as pension plan decisions, that is, they could choose one of the two other risky plans. Finally, Treatment Group 2 was similar to Treatment Group 1, except that participants had a fourth option: a risk-free plan.

Data collection started on July 29, 2015, through a post on the Facebook $₫$ personal page of one of the researchers, and six paid advertisements on this social network, kept until August 25, 2015. At this stage, we had achieved 192 answered questionnaires.

On August 26, 2015, we started data collection, both through a paid advertisement on LinkedIn(C) and an announcement on the personal page of one of the researchers. These invitations remained until October 7, 2015. In this second social network, we received 31 answered questionnaires. The questionnaire was also available on the personal page of the second researcher, from December 12 to 29, 2015, with a response of 18 questionnaires. On December 30, 2015, we shut the access to the research virtual address.

We got 241 answered questionnaires, those from 77 participants of the control group, 86 from Treatment 1 and 78 from Treatment 2 .

We adopted the following steps for data treatment:

(1) Identification of absent, incomplete or inconsistent values, which resulted in the exclusion of 33 respondents;

(2) Calculation of the amount that each participant should donate, following the procedure described early;

(3) Analysis of the descriptive statistics;

(4) Use of Mann-Whitney nonparametric tests for inferences on the results.

The participants' characteristics show that the profile of respondents does not represent the Brazilian population, in particular regarding education and per capita income.

In the final sample, $38.9 \%$ of the respondents were women and $61.1 \%$ men. Most of them $(55.8 \%)$ were married, while $37.5 \%$ were single, $5.3 \%$ divorced and $1.4 \%$ legally separated. All participants completed high school; $93.7 \%$ had an undergraduate degree and $73.0 \%$ had a graduate degree. Their average age was 35.76 years. 
For the economic profile of the participants, we used multiples of the minimum wage (MW). In 2015, this value was US\$204.88. We chose to present the different categories by ranges of MW because this is an important index in Brazil. A great part of the Brazilian workers (over $80 \%$ ) receives up to two MW monthly. The MW is also important because no social security benefit (by age or time of contribution) from the Social Security General Regime (RGPS) can be less than one MW. Most of the respondents $(57.2 \%)$ had a monthly income equal or above five MWs. Only $5.3 \%$ of the sample had an income less or equal to one MW. This is another evidence that the sample of respondents was not representative of the Brazilian workers. For example, in 2015, the average income in Brazil was US\$289.38.

\section{Results}

In this section, we present the findings of the experimental treatments. Due to an unexpected computational problem, the software did not register the answers for period 1 . For this reason, the analyses regard the figures for periods $2,3,4$ and 5 .

\subsection{Respondents' behavior in the control group}

We start with the choices of pension plans, from periods 2 to 5 , separated by gender. We use the term Plan $p_{i}$ for the plan chosen in the period $i$. For example, we name the plan chosen in period 2 as Plan_p2. We used this classification in both the control and the treatment groups. We noticed that when individuals had the three alternative pension plans, with high, medium and low risk levels (plan 1, plan 2 and plan 3), in all periods, they chose the plan of highest risk.

In period $2,57.7 \%$ of the individuals of the control scenario chose plan 1 (the riskiest). The medium risk plan (plan 2) was the only one that showed an equal distribution of men and women, although the option for this plan comprised $20 \%$ of the total of men who participated in the research, and approximately $35 \%$ of the women.

In period 3, most of the sample chose to keep the risky behavior; $57.1 \%$ continued with plan 1. Similarly, there was no change in the choice behavior of pension plans by gender.

In period 4 , as reported in Table 1 , there was a slight increase (three respondents) in the number of individuals who chose the less risky plan (plan 3). We also observed that from the 11 respondents who chose plan 3, nine were women. This was expected because female

\begin{tabular}{llccc}
\hline & & & Gender & \\
Risk & Distribution & Female & Male & Total \\
\hline High $(1.4 \%$ or $5.2 \%)$ & $N$ & 14 & 26 & 40 \\
& \% in plano_p4 & 35.0 & 65.0 & 100.0 \\
Medium $(1.5 \%$ or $4.3 \%)$ & \% of the total & 19.7 & 36.6 & 56.3 \\
& $N$ & 10 & 10 & 20 \\
Low $(1.6 \%$ or $3.4 \%)$ & \% in plano_p4 & 50.0 & 50.0 & 100.0 \\
& \% of the total & 14.1 & 14.1 & 28.2 \\
Total & \% in plano_p4 & 2 & 9 & 11 \\
& \% of the total & 18.2 & 81.8 & 100.0 \\
& $N$ & 2.8 & 12.7 & 15.5 \\
& \% in plano_p4 & 36.6 & 45 & 71 \\
& \% of the total & 36.6 & 63.4 & 100.0 \\
& & 63.4 & 100.0
\end{tabular}

Source(s): Prepared by the authors
Automatic enrollment and employer match

289 
REGE 27,3

290 behavior is associated with a risk-averse profile (Bajtelsmith, Bernasek, \& Jianakoplos, 1999; Bernasek \& Shwiff, 2001). The proportion of male subjects in the total was about $20 \%$, and of females was 7.7\%, keeping a considerable difference. Clark, Hanson, and Mitchell (2016) found that men and people that are more educated make active choices, confirming this trend.

Finally, in period 5, the last before retirement, individuals kept a similar behavior as in previous periods. Hence, throughout the four periods in which the participants of the control group contributed to a plan, when asked to indicate one among the three pension plans, the overriding option was plan 1, the high risk plan.

\subsection{Respondents' behavior in treatment group 1}

In this group, we manipulated the scenario so that the respondent would be automatically enrolled in one of the plans (plan 2, medium risk) in the initial period, with a counterpart of the same value from the employer, for each amount saved by the employee in that plan (default). The purpose was to check if the respondent would keep a status quo behavior (remaining in this plan) or migrate to another plan in subsequent periods.

In period 2, the expected effect of scenario manipulation on the choice of the DC pension plan did not occur; most of the respondents in this group opted (as in the control scenario) for the riskiest plan. There was a similar proportion in the choices of men and women. Table 2 presents these results.

In broad terms, participants kept their choices in periods 3,4 and 5, with most of them choosing the riskiest plan (plan 1), with the percentages - $50.6 \%, 53.2 \%$ and $51.9 \%$, respectively. Such results allow us to refute hypothesis $\mathrm{H} 1$ for Treatment 1 . This hypothesis assumed that "individuals automatically enrolled in a supplementary pension plan do not change their decision in subsequent choices". We came to this conclusion based on the results of the nonparametric Mann-Whitney test, shown in Table 3 for periods 2, 3, 4 and 5.

Results shown in Table 3 suggest that there is no statistically significant difference between Treatment group 1 (compulsory enrollment) and the control group, at the $5 \%$ level ( $p$-value $>0.05$ ), regarding the choice of pension plans in any of the periods, for the scenarios presented to respondents. These findings contradict those of Hey (2008), the literature about automatic enrollment and default (Benartzi, 2001; Beshears, Choi, Laibson, \& Madrian, 2008, 2011, 2018; Chow, Laibson, Madrian, \& Metrick, 2002, 2004, 2009; Clark, Hanson \& Mitchell, 2016; Madrian \& Shea, 2001), and employer match (Andrews, 1992; Chow, Laibson, Madrian, \& Metrick, 2002; Papke \& Poterba, 1995).

\begin{tabular}{llccr}
\hline & & & Gender & \\
Risk & Distribution & Female & Male & Total \\
\hline High $(1.4 \%$ or $5.2 \%)$ & $N$ & 17 & 22 & 39 \\
& \% in plano_p2 & 43.6 & 56.4 & 100.0 \\
Medium $(1.5 \%$ or $4.3 \%)$ & \% of the total & 22.4 & 28.9 & 51.3 \\
& $N$ & 10 & 18 & 28 \\
Low $(1.6 \%$ or $3.4 \%)$ & \% in plano_p2 & 35.7 & 64.3 & 100.0 \\
& \% of the total & 13.2 & 23.7 & 36.8 \\
Total & \% in plano_p2 & 4 & 5 & 9 \\
& \% of the total & 5.3 & 55.6 & 100.0 \\
& $N$ \% in plano_p2 & 31 & 6.6 & 11.8 \\
& \% of the total & 40.8 & 59.2 & 100.0 \\
& & 40.8 & 59.2 & 100.0
\end{tabular}

Source(s): Prepared by the authors
Pension plans and gender in treatment 1 period 2 (plan_p2)

\footnotetext{
Source(s): Prepared by the authors
} 
4.3 Respondents' behavior in treatment group 2

In the initial period, the respondent was automatically enrolled in plan 2 (medium risk), with a counterpart from the employer of $100 \%$ of the amount saved by the employee. He was also offered the alternative plan 4, the risk-free plan. This strategy sought to check if the respondent would keep this plan or migrate to another plan in subsequent periods.

We can observe (Table 4) that in Treatment 2 scenario there is a higher number of respondents that opted for the automatic enrollment plan (although the total for this plan and for the riskiest plan are basically the same), showing a possible effect of this manipulation and confirming the findings of Hey (2008). This result is different from that observed in Treatment 1 scenario, where compulsory enrollment did not seem to affect the respondents' choices.

Table 4 shows that only $20.3 \%$ of the respondents allocated to Treatment 2 scenario chose the risk-free plan 4 . Results also indicate that men were more risk-taking in this scenario, confirming the findings of the previous scenario. In the plan with automatic enrollment (medium risk), the number of individuals from both genders was basically the same, while in the riskiest plan males prevailed, confirming former evidence (Bajtelsmith, Bernasek, \& Jianakoplos, 1999; Bernasek \& Shwiff, 2001).

We noticed a behavior similar to that of period 2 in periods 3 and 4, with a higher proportion of respondents remaining in the plan in which they had been automatically enrolled, although the difference from plan 1 (high risk) was not very significant. In period 2 , the percentage of those who chose plan 2 (medium risk) and the percentage of those who chose

\begin{tabular}{lcccr}
\hline & & \multicolumn{2}{c}{ Treatment 1 } & \\
\hline$Z$ & Período_2 & Período_3 & Período_4 & Período_5 \\
$p$-value (two-tailed) & -0.374 & -0.816 & -0.085 & -0.821 \\
& 0.709 & 0.414 & 0.932 & 0.412
\end{tabular}

Source(s): Prepared by the authors

Automatic enrollment and employer match

\begin{tabular}{|c|c|c|c|c|}
\hline \multirow[b]{2}{*}{ Risk } & \multirow[b]{2}{*}{ Distribution } & \multicolumn{2}{|c|}{ Gender } & \multirow[b]{2}{*}{ Total } \\
\hline & & Female & Male & \\
\hline \multirow[t]{3}{*}{ High $(1.4 \%$ or $5.2 \%)$} & $N$ & 6 & 15 & 21 \\
\hline & $\%$ in plano_p2 & 28.6 & 71.4 & 100.0 \\
\hline & $\%$ of the total & 10.2 & 25.4 & 35.6 \\
\hline \multirow[t]{3}{*}{ Medium $(1.5 \%$ or $4.3 \%)$} & $N$ & 10 & 12 & 22 \\
\hline & $\%$ in plano_p2 & 45.5 & 54.5 & 100.0 \\
\hline & $\%$ of the total & 16.9 & 20.3 & 37.3 \\
\hline \multirow[t]{3}{*}{ Low $(1.6 \%$ or $3.4 \%)$} & $N$ & 2 & 2 & 4 \\
\hline & $\%$ in plano_p2 & 50.0 & 50.0 & 100.0 \\
\hline & $\%$ of the total & 3.4 & 3.4 & 6.8 \\
\hline \multirow[t]{3}{*}{ Risk-free (2.1\%) } & $N$ & 6 & 6 & 12 \\
\hline & $\%$ in plano_p2 & 50.0 & 50.0 & 100.0 \\
\hline & $\%$ of the total & 10.2 & 10.2 & 20.3 \\
\hline \multirow[t]{3}{*}{ Total } & $N$ & 24 & 35 & 59 \\
\hline & $\%$ in plano_p2 & 40.7 & 59.3 & 100.0 \\
\hline & $\%$ of the total & 40.7 & 59.3 & 100.0 \\
\hline
\end{tabular}

Note(s): *Plano_p2 represents the plan chosen in period 2; ** the difference between the plans is the interest rate on the amount applied

Source(s): Prepared by the authors

Table 3. Nonparametric test for the mean difference (treatment 1 and control)
Table 4.

Pension plans and gender in treatment 2 , period 2 
REGE 27,3

292

plan 1 were the same: $35.6 \%$. In period 4 , these percentages were $37.3 \%$ and $28.8 \%$, respectively. In period 5 (the last before retirement), for Treatment 2 scenario, there was a migration of respondents from the high and medium risk plans to the risk-free plan, as Table 5 shows.

The Mann-Whitney test confirmed the change observed in the behavior of Treatment 2 respondents (Table 6). The results suggest that there is a statistically significant difference between Treatment 2 group (compulsory enrollment and the alternative of a risk-free plan) and the control group at the $5 \%$ level $(p$-value $<0.01)$, in all periods, for the scenarios presented to respondents. These findings reveal that automatic enrollment (Choi, Laibson, Madrian, \& Metrick, 2003) and the funds design (Agnew, Anderson, Gerlach, \& Szykman, 2008; Basu \& Drew, 2007; Beshears, Choi, Laibson, \& Madrian, 2013; Pang \& Warshawsky, 2008) contribute to the continuation of resource allocation for retirement, and increase the participation rate in pension plans.

In addition, we carried out the Mann-Whitney test to check the difference of means between Treatment 1 (compulsory enrollment) and Treatment 2 (compulsory enrollment and the alternative of a risk-free pension plan). The results indicate that Treatment 2 had an effect on pension plans' choices also when compared to the design proposed by Treatment 1 , at the $5 \%$ level of significance $(p$-value $<0.05)$.

These results suggest a closer focus at the two characteristics of Treatment 2: automatic enrollment and the presence of a risk-free pension plan. Although in Treatment 2 more respondents opted for the plan in which they had been automatically enrolled in period 1 , such a result is different from that of Treatment 1 , which has this same attribute. However,

\begin{tabular}{|c|c|c|c|c|}
\hline \multirow[b]{2}{*}{ Risk } & \multirow[b]{2}{*}{ Distribution } & \multicolumn{2}{|c|}{ Gender } & \multirow[b]{2}{*}{ Total } \\
\hline & & Female & Male & \\
\hline \multirow[t]{3}{*}{ High $(1.4 \%$ or $5.2 \%)$} & $N$ & 5 & 9 & 14 \\
\hline & \% in plano_p5 & 35.7 & 64.3 & 100.0 \\
\hline & $\%$ of the total & 8.3 & 15.0 & 23.3 \\
\hline \multirow[t]{3}{*}{ Medium $(1.5 \%$ or $4.3 \%)$} & $N$ & 8 & 12 & 20 \\
\hline & \% in plano_p5 & 40.0 & 60.0 & 100.0 \\
\hline & $\%$ of the total & 13.3 & 20.0 & 33.3 \\
\hline \multirow[t]{3}{*}{ Low $(1.6 \%$ or $3.4 \%)$} & $N$ & 2 & 1 & 3 \\
\hline & \% in plano_p5 & 66.7 & 33.3 & 100.0 \\
\hline & $\%$ of the total & 3.3 & 1.7 & 5.0 \\
\hline \multirow[t]{3}{*}{ Risk-free $(2.1 \%)$} & $N$ & 9 & 14 & 23 \\
\hline & \% in plano_p5 & 39.1 & 60.9 & 100.0 \\
\hline & $\%$ of the total & 15.0 & 23.3 & 38.3 \\
\hline \multirow[t]{3}{*}{ Total } & $N$ & 24 & 36 & 60 \\
\hline & \% in plano_p5 & 40.0 & 60.0 & 100.0 \\
\hline & $\%$ of the total & 40.0 & 60.0 & 100.0 \\
\hline
\end{tabular}

Table 5.
Pension plans and gender in treatment 2 , period 5

Source(s): Prepared by authors

Table 6.

Nonparametric test for the difference of means (treatments 2 and control)
Treatment 2

\begin{tabular}{|c|c|c|c|c|}
\hline & \multicolumn{4}{|c|}{ Treatment 2} \\
\hline & Período_2 & Período_3 & Período_4 & Período_5 \\
\hline$Z$ & -2.543 & -2.430 & -3.900 & -4.715 \\
\hline$p$-value (two-tailed) & 0.011 & 0.015 & 0.000 & 0.000 \\
\hline \multicolumn{5}{|c|}{ Source(s): Prepared by the authors } \\
\hline
\end{tabular}


maybe the simple presence of a fourth option in Treatment 2 (the risk-free plan, plan 4) has affected the choice of pension plans, since the risk-free plan was the preferred only in period 5 .

Such findings provide the basis for partially rejecting hypothesis H1(a) - that a supplementary pension plan with lower risk gets more admissions from temporarily inconsistent individuals compared to the other plans offered, as predicted by Cox \& Harrison (2008) and Hey (2008).

\subsection{Risk profile and transition over time}

An interesting aspect for analysis is how the choices of the risk profiles varied over time, that is, over the periods of the experiment. We did it through transition matrices, where the rows represent the choices made in period $t$ and the columns the choices made in period $t+1$. Unfortunately, due to an unexpected computational problem mentioned before, the software did not register the answers for period 1 . Thus, all the analyses of transition matrices focus on periods $2-5$.

4.4.1 Transition from period 2 to period 3. The transition matrix (Table 7) showed a high inertia in risk choices among individuals, for those who made the extreme choices (risk-free and high risk). Of the 13 respondents who chose the risk-free plan in period 2 , only one $(7.7 \%)$ chose another plan, the low risk, in the third period. On the other hand, 26 respondents who opted for the low risk plan in period 1 distributed themselves in period 2 as follows: 18 remained in the same plan $(69.2 \%)$, five migrated to the moderate risk plan $(19.2 \%)$, two chose the riskier plan $(7,7 \%)$ and one moved to the risk-free plan $(3.8 \%)$. In the case of the moderate risk plan, $84.8 \%$ repeated their choice and for the riskier plan, $93.1 \%$ remained in the same plan from period 2 to 3 .
Automatic enrollment and employer match

293

\begin{tabular}{|c|c|c|c|c|c|c|c|}
\hline \multicolumn{8}{|c|}{ Transition from period 2 to period 3} \\
\hline Risk-free & 13 & $92.3 \%$ & $7.7 \%$ & $0.0 \%$ & $0.0 \%$ & $100.0 \%$ & \\
\hline Low risk & 26 & $3.8 \%$ & $69.2 \%$ & $19.2 \%$ & $7.7 \%$ & $100.0 \%$ & Table 7. \\
\hline Moderate risk & 66 & $0.0 \%$ & $7.6 \%$ & $84.8 \%$ & $7.6 \%$ & $100.0 \%$ & Matrix transition from \\
\hline High risk & 101 & $0.0 \%$ & $2.0 \%$ & $5.0 \%$ & $93.1 \%$ & $100.0 \%$ & period 2 to period 3 \\
\hline
\end{tabular}

\begin{tabular}{lrrrrrrr}
\hline \multicolumn{2}{l}{ Transition from period 3 to period 4} & & & & \\
\multicolumn{2}{l}{$N$} & Risk-free & Low risk & Moderate risk & High risk & Total & \\
\cline { 1 - 4 } Risk-free & 13 & $100.0 \%$ & $0.00 \%$ & $0.0 \%$ & $0.0 \%$ & $100.0 \%$ & \\
Low risk & 26 & $0.0 \%$ & $53.8 \%$ & $23.1 \%$ & $23.1 \%$ & $100.0 \%$ & Table 8. \\
Moderate risk & 66 & $0.0 \%$ & $7.6 \%$ & $84.8 \%$ & $7.6 \%$ & $100.0 \%$ & Matrix transition from \\
High risk & 101 & $3.0 \%$ & $5.0 \%$ & $5.9 \%$ & $86.1 \%$ & $100.0 \%$ & period 3 to period 4 \\
\hline
\end{tabular}

\begin{tabular}{|c|c|c|c|c|c|c|c|}
\hline \multicolumn{8}{|c|}{ Transition from period 4 to period 5} \\
\hline & $N$ & Risk-free & Low risk & Moderate risk & High risk & Total & \\
\hline Risk-free & 16 & $100.0 \%$ & $0.0 \%$ & $0.0 \%$ & $0.0 \%$ & $100.0 \%$ & \\
\hline Low risk & 24 & $8.3 \%$ & $75.0 \%$ & $8.3 \%$ & $8.3 \%$ & $100.0 \%$ & Table 9. \\
\hline Moderate risk & 68 & $1.5 \%$ & $4.4 \%$ & $85.3 \%$ & $8.8 \%$ & $100.0 \%$ & Matrix transition from \\
\hline High risk & 98 & $4.1 \%$ & $2.0 \%$ & $3.1 \%$ & $90.8 \%$ & $100.0 \%$ & period 4 to period 5 \\
\hline
\end{tabular}


REGE 27,3
4.4.2 Transition from period 3 to period 4. The results of Table 8 were similar to those reported in Table 7. The only noticeable exception was the low risk plan. About half of the subjects $(53.8 \%)$ made another choice in the fourth period, with a huge increase in the transition to the high risk plan. Those who chose the risk-free plan kept their choice in the following period. For respondents who joined the moderate risk plan in period 3, the percentage of repeated choices $(84.8 \%)$ was the same as in the previous period. Finally, there was a slight increase in migration from the high risk to the other plans.

4.4.2 Transition from period 4 to period 5. The Table 9 reports the results of the final transition, from period 4 to period 5 . The most important change occurred for the low risk plan, where the inertia (the same choice from one period to another) increased from $53.8 \%$ in Figure 3 to $75.0 \%$ in Figure 4 . For the other plans, percentages remained barely the same, with minor increases in changes from other plans. Repeating the pattern of the past periods, all 16 subjects who chose the risk-free plan in period 4 repeated their choice in period 5 . For the moderate and high risk plans, the figures were a little lower $(85.3 \%$ and $90.8 \%)$.

In short, the analysis of the transition matrices provided evidence that there is a remarkable inertia of the participants, when choosing their risk profiles along their working life. These results confirm previous findings (Auger, Devinney, Dowling, \& Eckert, 2016; Choi, Laibson, Madrian, \& Metrick, 2004; Foster, 2017; Madrian \& Shea, 2001) on individual behavior, regarding investments and retirement decisions. The small changes in the number of subjects who chose each type of plan may be a proxy for stable preferences in their working life cycle. We also noticed that respondents were not prone to make riskier choices in period 5, although this was the last before retirement.

\section{Conclusion}

This study attempted to identify the arrangements of defined contribution pension plans, regarding the continuity of resource allocation for retirement. The results suggest that the design of a pension plan with automatic enrollment, parity contribution and risk-free seems to influence the decision for choosing this plan, with a longer permanence compared to the control scenario, where the plan did not present such attributes. In contrast, there was no evidence that the pension plan design with just the automatic enrollment and parity counterpart of the employer affected the choice. Therefore, in response to the research question, the main result indicates a longer permanence of individuals in a risk-free plan with compulsory enrollment.

The interpretation of this result is that the design of public policies for pension plans should provide incentives for individuals to take appropriate decisions regarding their retirement savings. This conclusion meets the foundations of nudging (Hausman \& Welch, 2010; Orenstein, 2013; Thaler \& Sunstein, 2008), and is aligned with Gregor and Lee-Archer (2016) recommendations.

These results confirm findings of behavioral economics, which indicate that the instruments of personal commitment and automatic enrollment, associated with the high default contribution rate (default), can increase the accumulated wealth for retirement (Chetty, 2015; Choi, Laibson, Madrian, \& Metrick, 2004). However, the outcomes align with the set of nonconclusive results about the effect of employer's counterpart on workers' savings, which indicate a null relationship (Choi, Laibson, Madrian, \& Metrick, 2004), a positive relationship (Papke \& Poterba, 1995) and a nonlinear relationship (Engelhardt \& Kumar, 2003).

Finally, when evaluating the influence of the experimental treatments on the choice of pension plans, there is evidence that:

(1) In experimental scenario 1 (automatic enrollment and full counterpart by the plan sponsor), most of the participants preferred the riskiest plan in all periods of the 
experiment. In addition, we observed no statistically significant difference between Treatment 1 and the control groups, thus rejecting hypothesis H1(b).

(2) In experimental scenario 2 (automatic enrollment and full counterpart by the employer, in addition to the alternative of a risk-free plan), most of the participants preferred the risk-free plan in period 5 . At the same time, most of the individuals participated in the plan in which they were automatically enrolled in periods 2 and 4 . Such results allowed us to partially reject hypothesis H1(a).

These results, taken together, partially reinforce the evidence provided by the literature that automatic enrollment increases participation in pension plans (Benartzi \& Thaler, 2007; Choi, Laibson, Madrian, \& Metrick, 2004; Clark \& Pelletier, 2019; Madrian \& Shea, 2001), and that individuals prefer risk-free plans to riskier plans (Hey, 2008). But this result is slightly different from Inkmann \& Shi's (2016), who found a negative relationship between age and risky assets, in a DC default plan.

Research findings can be relevant for the design of public policies for private pension plans, by suggesting that compulsory enrollment can be a default in plans offered by employers. The results encourage the inclusion of behavioral elements in the design of the pension system, such as nudges.

The results can contribute to the formulation of better public policies. Goldin, Homonoff, \& Tucker-Ray (2017) report that a simple nudge increased the participation of military staff members in pension plans in the USA. A second positive example is the effectiveness of an experiment to increase participation in the Ahorra + program in Spain (Garcia \& Vila, 2018). Another interesting area to highlight is the digital nudge (Gregor \& Lee-Archer, 2016). There is a long way to go for public administration, with very low costs and positive results for the whole society. However, it is necessary to design potential nudges very carefully, in order to improve the architecture of choices. This is the big challenge for policymakers.

A limitation of the research is the fact that the sample was not representative of the population, hence not allowing generalization. This is because we used social media ads to prospect respondents. For future research, we suggest applying different amounts of employer match for pension plans, and other forms of incentive for the enrollment and retention of employees in pension plans, such as a tax benefit.

\section{References}

Agnew, J.R., Anderson, L.R., Gerlach, J.R., \& Szykman, L.R. (2008). Who chooses annuities? An experimental investigation of the role of gender, framing, and defaults. American Economic Review, 98(2), 418-22, doi: 10.1257/aer.98.2.418.

Ahern, N.R. (2005). Using the Internet to conduct research. Nurse Researcher, 13(2).

Ameriks, J., \& Zeldes, S.P. (2004). How do household portfolio shares vary with age. Working paper, Columbia University, 1-87, Available at: https:/www0.gsb.columbia.edu/mygsb/faculty/ research/pubfiles/16/Ameriks_Zeldes_age_Sept_2004d.pdf.

Andrews, E.S. (1992). The growth and distribution of 401(k) plans. In J.A. Turner, \& D.J. Beller (Eds), Trends in Pensions 1992. Washington, DC: U.S. Department of Labor, 149-176.

Auger, P., Devinney, T., Dowling, G., \& Eckert, C. (2016). Inertia and discounting in the selection of socially responsible investments: An experimental investigation. Annals in Social Responsibility, 2(1), 29-47.

Bajtelsmith, V.L., Bernasek, A., \& Jianakoplos, N.A. (1999). Gender differences in defined contribution pension decisions. Financial Services Review, 8, 1-10, doi: 10.1016/s1057-0810(99)00030-x.

Basu, A.K., \& Drew, M.E. (2007). Portfolio size and lifecycle asset allocation in pension funds, Available at: http://eprints.qut.edu.au/14450/1/14450.pdf.
Automatic
enrollment and
employer
match

295 
REGE 27,3

Benartzi, S. (2001). Excessive extrapolation and the allocation of $401 \mathrm{k})$ accounts to company stock. The Journal of Finance, 56(5), 1747-1764, doi: 10.1111/0022-1082.00388.

Benartzi, S., \& Thaler, R.H. (2007). Heuristics and biases in retirement savings behavior. Journal of Economic Perspectives, 81-10, doi: 10.1257/jep.21.3.81.

Bernasek, A., \& Shwiff, S. (2001). Gender, risk, and retirement. Journal of economic issues, 35(2), $345-356$.

Beshears, J., Choi, J.J., Laibson, D., \& Madrian, B.C. (2008). How are preferences revealed?. Journal of Public Economics, 92(8-9), 1787-1794, doi: 10.1016/j.jpubeco.2008.04.010.

Beshears, J., Choi, J.J., Laibson, D., \& Madrian, B.C. (2010). The impact of employer matching on savings plan participation under automatic enrollment. In Research findings in the Economics of Aging: University of Chicago Press, Chicago, 311-327.

Beshears, J., Choi, J.J., Laibson, D., \& Madrian, B.C. (2011). Behavioral economics perspectives on public sector pension plans. Journal of Pension Economics and Finance, 10(2), 315-336, doi: 10. 1017/S1474747211000114.

Beshears, J., Choi, J.J., Laibson, D., \& Madrian, B.C. (2013). Simplification and saving. Journal of Economic Behavior and Organization, 95, 130-145, doi: 10.1016/j.jebo.2012.03.007.

Beshears, J., Choi, J.J., Laibson, D., \& Madrian, B.C. (2017). Does aggregated returns disclosure increase portfolio risk taking?. The Review of Financial Studies, 30(6), 1971-2005, doi: 10.1093/rfs/ hhw086.

Beshears, J., Choi, J.J., Laibson, D., \& Madrian, B.C. (2018). Behavioral household finance, In Handbook of Behavioral Economics: Applications and Foundations 1, North-Holland, 1, 177-276.

Binswanger, J., \& Carman, K.G. (2012). How real people make long-term decisions: The case of retirement preparation. Journal of Economic Behavior \& Organization, 81(1), 39-60, doi: 10. 1016/j.jebo.2011.08.010.

Brown, J.R., Kapteyn, A., \& Mitchell, O.S. (2016). Framing and claiming: How information-framing affects expected social security claiming behavior. Journal of Risk and Insurance, 83(1), 139-62, doi: 10.1111/j.1539-6975.2013.12004.x.

Bütler, M., \& Teppa, F. (2007). The choice between an annuity and a lump sum: Results from Swiss pension funds. Journal of Public Economics, 91(10), 1944-1966, doi: 10.1016/j.jpubeco.2007. 09.003.

Butt, A., Donald, M.S., Foster, F.D., Thorp, S., \& Warren, G.J. (2018). One size fits all? Tailoring retirement plan defaults. Journal of Economic Behavior \& Organization, 145, 546-566, doi: 10. 1016/j.jebo.2017.11.022.

Carroll, G.D., Choi, J.J., Laibson, D., Madrian, B.C., \& Metrick, A. (2009). Optimal defaults and active decisions. The Quarterly Journal of Economics, 124(4), 1639-1674, doi: 10.1162/qjec.2009.124. 4.1639 .

Chetty, R. (2015). Behavioral economics and public policy: A pragmatic perspective. American Economic Review, 105(5), 1-33, doi: 10.3386/w20928.

Choi, J.J., Laibson, D., Madrian, B.C., \& Metrick, A. (2002). Defined contribution pensions: Plan rules, participant decisions, and the path of least resistance. In J.M. Poterba (Ed.), Tax policy and the economy, Cambridge, MA: MIT Press, 16, 67-113.

Choi, J.J., Laibson, D., Madrian, B.C., \& Metrick, A. (2003). Optimal defaults. American Economic Review, 93(2), 180-185, doi: 10.1257/000282803321947010.

Choi, J.J., Laibson, D., Madrian, B., \& Metrick, A. (2004). Employees' investment decisions about company stock. NBER Working Paper 10228. Available at: https:/www.nber.org/papers/ w10228.

Choi, J.J., Laibson, D., \& Madrian, B.C. (2009). Reducing the complexity costs of 401 (k) participation through quick enrollment, In Developments in the Economics of Aging: University of Chicago Press, Chicago, 57-82. 
Clark, G.L. (2011). Myopia and the global financial crisis Context-specific reasoning, market structure, and institutional governance. Dialogues in Human Geography, 1(1), 4-25, doi: 10.1177/ 2043820610386318.

Clark, R.L., \& Pelletier, D. (2019). Does automatic enrollment increase contributions to supplement retirement programs by K-12 and university employees?. NBER Working Paper Series (26263), doi: 10.1017/CBO9781107415324.004.

Clark, R.L., Hanson, E., \& Mitchell, O.S. (2016). Lessons for public pensions from Utah's move to pension choice. Journal of Pension Economics and Finance, 15(3), 285-310, doi: 10.1017/ S1474747215000426.

Clark, R.L., Hammond, R.G., Morrill, M.S., \& Khalaf, C. (2017). Nudging retirement savings: A field experiment on supplemental plans. NBER Working Paper 23679, 1-52, doi: 10.3386/w23679.

Collard, S. (2013). Workplace pension reform: Lessons from pension reform in Australia and New Zealand. Social Policy and Society, 12(1), 123-134, doi: 10.1017/S1474746412000474.

Conselho Nacional de Saúde (2012). Resolução no 466, de 12 de dezembro de 2012. Available at: http:// www.conselho.saude.gov.br/web_comissoes/conep/index.html.

Cox, J.C., \& Harrison, G.W. (2008). Risk aversion in experiments: an introduction. In Risk Aversion in Experiments. Emerald JAI Press Cornwall, Bingley, 12, 1-7.

Cremer, H., \& Pestieau, P. (2011). Myopia, redistribution and pensions. European Economic Review, 55(2), 165-175, doi: 10.1016/j.euroecorev.2010.07.002.

Cronqvist, H., \& Thaler, R.H. (2004). Design choices in privatized social-security systems: Learning from the Swedish experience. American Economic Review, 94(2), 424-428, doi: 10.1257/ 0002828041301632.

Cronqvist, H., Thaler, R.H., \& Yu, F. (2018). When nudges are forever: Inertia in the Swedish premium pension plan. AEA Papers and Proceedings, 108(May), 153-158, doi: 10.1257/pandp. 20181096.

Dahlquist, M., \& Martinez, J.V. (2015). Investor inattention: A hidden cost of choice in pension plans? European Financial Management, 21(1), 1-19, doi: 10.1111/j.1468-036X.2013.12008.x.

Dobrescu, L.I., Fan, X., Bateman, H., Newell, B.R., Ortmann, A., \& Thorp, S. (2017). Retirement savings: A tale of decisions and defaults. The Economic Journal, 128(610), 1047-1094, doi: 10.1111/ ecoj.12447.

Engelhardt, G.V., \& Kumar, A. (2003). Understanding the impact of employer matching on 401(k) saving. Research Dialogue, 76, 1-12, doi: 10.1016/j.jpubeco.2007.02.009.

Feldstein, M., \& Liebman, J.B. (2002). Social security. In A.J. Auerbach \& M. Feldstein (Eds), Handbook of Public Economics, 4, Amsterdam: North-Holland, 2245-2324.

Foster, L. (2017). Young people and attitudes towards pension planning. Social Policy and Society, 16(1), 65-80, doi: 10.1017/S1474746415000627.

Garcia, J.M., \& Vila, J. (2018). Nudging long-term saving: The Ahorra+ program. Journal of Behavioral Economics for Policy, 2(2), 49-53. Available at: https://sabeconomics.org/wordpress/wp-content/ uploads/JBEP-2-2-6.pdf.

Goda, G.S., \& Manchester, C.F. (2013). Incorporating employee heterogeneity into default rules for retirement plan selection. Journal of Human Resources, 48(1), 198-235, doi: 10.3386/w16099.

Goldin, J., Homonoff, T., \& Tucker-Ray, W. (2017). Retirement contribution rate nudges and plan participation: Evidence from a field experiment. American Economic Review: Papers and Proceedings, 107(5), 456-461, doi: 10.1257/aer.p20171059.

Graham, F., \& Isaac, A.G. (2002). The behavioral life-cycle theory of consumer behavior: Survey evidence. Journal of Economic Behavior and Organization, 48(4), 391-401, doi: 10.1016/S01672681(01)00242-6.

Gregor, S., \& Lee-Archer, B. (2016). The digital nudge in social security administration. International Social Security Review, 69(3-4), 63-83, doi: 10.1111/issr.12111.

Automatic
enrollment and
employer
match

(1)


REGE 27,3
Handcock, M.S., \& Gile, K.J. (2010). Modeling social networks from sampled data. The Annals of Applied Statistics, 4(1), 5-2, doi: 10.1214/08-AOAS221.

Hausman, D.M., \& Welch, B. (2010). Debate: To nudge or not to nudge. Journal of Political Philosophy, 18(1), 123-136, doi: 10.1111/j.1467-9760.2009.00351.x.

Hey, J. (2008). Exploring the experimental economics approach in pensions. Working Paper, Department for Work and Pensions, 43, 1-112.

Inkmann, J., \& Shi, Z. (2016). Life-cycle patterns in the design and adoption of default funds in DC pension plans. Journal of Pension Economics and Finance, 15(04), 429-454, doi: 10.1017/ S1474747214000511.

Kahneman, D. (2012). Rápido e devagar: Duas formas de pensar. São Paulo: Objetiva.

Keim, D.B., \& Mitchell, O.S. (2018). Simplifying choices in defined contribution retirement plan design: A case study. Journal of Pension Economics and Finance, 17(3), 363-384, doi: 10.1017/ S1474747217000336.

Kling, C.L., Phaneuf, D.J., \& Zhao, J. (2012). From exxon to BP: Has some number become better than no number?. Journal of Economic Perspectives, 26(4), 3-26, doi: 10.1257/jep.26.4.3.

Knoll, M.A.Z. (2010). The role of behavioral economics and behavioral decision making in Americans' retirement savings decisions. Social Security Bulletin, 70(4), 1-23, doi: 10.1007/s11149-0119180-1.

MacLeod, P., Fitzpatrick, A., Hamlyn, B., Jones, A., Kinver, A., \& Page, L. (2012). Attitudes to pensions: The 2012 survey. Department of Work and Pension: Research Report, 813, 1-162.

Madrian, B.C., \& Shea, D.F. (2001). The power of suggestion: Inertia in 401(k) participation and savings behavior. The Quarterly Journal of Economics, 116(4), 1149-1187, doi: 10.1162/ 003355301753265543.

Mitchell, O.S., Mottola, G.R., Utkus, S.P., \& Yamaguchi, T. (2006). The inattentive participant: Portfolio trading behavior in 401(K) plans. Michigan Retirement Research Center Research Paper 2006115, Available at: https://ssrn.com/abstract $=1094834$.

Modigliani, F., \& Brumberg, R. (1954). Utility analysis and the consumption function. In Kurihara K. (Ed.), Post-Keynesian Economics, New Brunswick, NJ: Rutgers University Press.

Mullainathan, S., \& Thaler, R.H. (2000). Behavioral economics. NBER Working Paper 7948, doi: 10. 3386/w7948.

Mulligan, C.B., \& Sala-i-Martin, X. (1999). Social security in theory and practice (II): Efficiency theories, narrative theories, and implications for reform. NBER Working Paper 7119, doi: 10.3386/w7119.

Munnell, A.H., \& Sundén, A. (Eds) (2004). Death and dollars: the role of gifts and bequests in America. Brookings Institution Press, Washington, p. 432.

Nessmith, W.E., Utkus, S.P., \& Young, J.A. (2007). Measuring the effectiveness of automatic enrollment. Vanguard Center for Retirement Research, 31(5), 1-20, Available at: www. vanguard.com/retirementresearch.

Nishiyama, S., \& Smetters, K. (2014). Financing old age dependency. Annual Review of Economics, 6(1), 53-76, doi: 10.1146/annurev-economics-080213-041304.

Orenstein, M.A. (2013). Pension privatization: Evolution of a paradigm. Governance, 26(2), 259-281, doi: $10.1111 /$ gove.12024.

Osman, K. (2017). Determinantes da procura por investimento em previdência privada: uma estimativa Logit (Master thesis), São Paulo, SP: Escola de Economia, Fundação Getúlio Vargas.

Pang, G., \& Warshawsky, M.J. (2008). Default investment options in defined contribution plans: A quantitative comparison. Pensions: An International Journal, 13(4), 221-226.

Papke, L.E., \& Poterba, J.M. (1995). Survey evidence on employer match rates and employee saving behavior in 401(k) plans. Economics Letters, 49(3), 313-317, doi: 10.1016/0165-1765(95) 00683-7. 
Prabhakar, R. (2017). Why do people opt-out or not opt-out of automatic enrolment? A focus group study of automatic enrolment into a workplace pension in the United Kingdom. Journal of European Social Policy, 27(5), 447-457, doi: 10.1177/0958928717717656.

Rudolph, H.P. (2019). Pension funds with automatic enrollment schemes: Lessons for Emerging Economies, Policy Research Working Paper 8726. World Bank, Available at: http://documents. worldbank.org/curated/en/368081549376313709/Pension-Funds-with-Automatic-Enrollment-Sch emes-Lessons-for-Emerging-Economies.

Samuelson, W., \& Zeckhauser, R. (1988). Status quo bias in decision making. Journal of Risk and

Automatic enrollment and employer match Uncertainty, 1(1), 7-59, Available at: https://ink.springer.com/article/10.1007/BF00055564.

Sandbrook, W., \& Ravi-Burslem, R. (2019). Communicating NEST pensions for "new" DC savers in the United Kingdom. Social Protection and Jobs Discussion Papers. World Bank, 1, 1-46, Available at: http://documents.worldbank.org/curated/en/574841556879345308/Communicating-NESTPensions-for-New-DC-Savers-in-the-United-Kingdom.

Shefrin, H.M., \& Thaler, R.H. (1988). The behavioral life-cycle hypothesis. Economic Inquiry, 26(4), 609-643.

Strotz, R.H. (1955). Myopia and inconsistency in dynamic utility maximization. The Review of Economic Studies, 23(3), 165, doi: 10.2307/2295722.

Thaler, R.H., \& Sunstein, C.R. (2008). Nudge: Improving decisions about health, wealth, and happiness. Yale University Press, New York, p. 320.

Xiao, J.J., \& Porto, N. (2019). Financial education and insurance advice seeking. The Geneva Papers on Risk and Insurance - Issues and Practice, 44(1), 20-35, doi: 10.1057/s41288-018-0108-1.

\section{Corresponding author}

Antonio Gualberto Pereira can be contacted at: antoniopereira@ufba.br

Associate Editor: Elizabeth Krauter

For instructions on how to order reprints of this article, please visit our website:

www.emeraldgrouppublishing.com/licensing/reprints.htm

Or contact us for further details: permissions@emeraldinsight.com 